\title{
Evaluating the Effects of Chemical Composition on Induction Heating Ability of $\mathrm{Fe}_{2} \mathrm{O}_{3}-\mathrm{CaO}-\mathrm{SiO}_{2}$ Glass Ceramics
}

\author{
Y. Y. Wang, B. Li, Y. L. Yu, and P. S. Tang \\ Department of Material Chemistry, Huzhou University, Huzhou 313000, China \\ Correspondence should be addressed to Y. Y. Wang; arince@hutc.zj.cn
}

Received 27 October 2015; Revised 1 March 2016; Accepted 21 March 2016

Academic Editor: Michele Iafisco

Copyright (c) 2016 Y. Y. Wang et al. This is an open access article distributed under the Creative Commons Attribution License, which permits unrestricted use, distribution, and reproduction in any medium, provided the original work is properly cited.

In order to investigate the relationship between induction heating ability of $\mathrm{Fe}_{2} \mathrm{O}_{3}-\mathrm{CaO}-\mathrm{SiO}_{2}$ glass ceramics and chemical composition, a series of glass ceramic samples with different chemical compositions were prepared by the sol-gel method. The structural, textural, and magnetic properties of the samples were analyzed and correlated with the $\mathrm{Fe}_{2} \mathrm{O}_{3}$ content. This is the first time work of its kind that evaluates the relationships between induction heating ability and chemical composition of $\mathrm{Fe}_{2} \mathrm{O}_{3}$-CaO$\mathrm{SiO}_{2}$ glass ceramics. The results showed that induction heating ability of $\mathrm{Fe}_{2} \mathrm{O}_{3}-\mathrm{CaO}-\mathrm{SiO}_{2}$ glass ceramics increased gradually with increasing magnetite content. Also, the induction heating ability became considerably better when a small amount of phosphorus was introduced. This study thus reveals a methodology to control the induction heating ability of $\mathrm{Fe}_{2} \mathrm{O}_{3}-\mathrm{CaO}-\mathrm{SiO}_{2}$ glass ceramics through modifying the chemical composition.

\section{Introduction}

Magnetic induction hyperthermia has been found to be a useful modality for cancer therapy recently and the thermoseed materials used in hyperthermia therapy have become a topic of increasing research focus [1-3]. The thermoseed material must be biocompatible and contain a magnetic phase to generate and dissipate the proper amount of heat under alternating magnetic fields. Ferromagnetic and bioactive glass ceramics are considered to be effective thermoseed materials for cancer therapy. In particular, $\mathrm{Fe}_{2} \mathrm{O}_{3}-\mathrm{CaO}-\mathrm{SiO}_{2}$ glass ceramics are of great interest to researchers, due to their excellent magnetic properties and good biological activity. Several $\mathrm{Fe}_{2} \mathrm{O}_{3}$ $\mathrm{CaO}-\mathrm{SiO}_{2}$ glass ceramics having a considerable amount of magnetic phases have been developed for this application [47]. In fact, hyperthermic cancer therapy using $\mathrm{Fe}_{2} \mathrm{O}_{3}-\mathrm{CaO}$ $\mathrm{SiO}_{2}$ ferromagnetic glass ceramics has already been reported to show excellent results in animal experiment [8-10].

$\mathrm{Fe}_{2} \mathrm{O}_{3}-\mathrm{CaO}-\mathrm{SiO}_{2}$ glass ceramics absorb magnetic energy and generate heat under the alternating magnetic field, as a result of eddy currents, Néel losses, and hysteresis losses [11-13]. There are several factors that influence the heat production rate [14], including the internal factors such as permeability, magnetic energy product, material size, and microstructure, as well as external factors such as magnetic field frequency and amplitude. The magnetic property was found to be one of the most significant factors affecting the induction heating ability of glass ceramics. Lee et al. explored the effect of the iron state on crystallization in $\mathrm{Fe}_{2} \mathrm{O}_{3}$ $\mathrm{CaO}-\mathrm{SiO}_{2}$ glasses [15], while Bretcanu et al. investigated the influence of crystallized $\mathrm{Fe}_{3} \mathrm{O}_{4}$ on magnetic properties of ferrimagnetic glass ceramics [16]. Magnetic properties of $\mathrm{CaO}$ $\mathrm{P}_{2} \mathrm{O}_{5}-\mathrm{Na}_{2} \mathrm{O}-\mathrm{Fe}_{2} \mathrm{O}_{3}-\mathrm{SiO}_{2}$ glass upon heat treatment were also analyzed by Shankhwar et al. [17]. However, to date, the effects of chemical compositions on the induction heating ability of $\mathrm{Fe}_{2} \mathrm{O}_{3}-\mathrm{CaO}-\mathrm{SiO}_{2}$ glass ceramics have not been reported.

The $\mathrm{Fe}_{2} \mathrm{O}_{3}-\mathrm{CaO}-\mathrm{SiO}_{2}$ glass ceramics with different compositions were prepared by the sol-gel method in this work. A small amount of phosphorus was introduced to increase the biological activity at the same time. Magnetic properties of the glass ceramic samples were evaluated and correlated mainly with the iron oxide content. The effect of $\mathrm{Fe}_{2} \mathrm{O}_{3}$ content on the induction heating ability of $\mathrm{Fe}_{2} \mathrm{O}_{3}-\mathrm{CaO}-\mathrm{SiO}_{2}$ glass ceramics has been investigated by analyzing the crystal phase and magnetic properties of the samples. This study also reveals a methodology to control the magnetic properties 
TABLE 1: Chemical compositions of different glass ceramic samples (wt\%).

\begin{tabular}{lcccc}
\hline Sample & $\mathrm{Fe}_{2} \mathrm{O}_{3}$ & $\mathrm{CaO}$ & $\mathrm{SiO}_{2}$ & $\mathrm{P}_{2} \mathrm{O}_{5}$ \\
\hline A1S1 & 15 & 42 & 43 & 0 \\
A1S3 & 20 & 39 & 41 & 0 \\
A1S5 & 25 & 36 & 39 & 0 \\
A1S7 & 30 & 34 & 36 & 0 \\
A1S9 & 35 & 32 & 33 & 0 \\
A2P1 & 30 & 39 & 30 & 1 \\
A2P7 & 28 & 37 & 28 & 7 \\
\hline
\end{tabular}

of $\mathrm{Fe}_{2} \mathrm{O}_{3}-\mathrm{CaO}-\mathrm{SiO}_{2}$ glass ceramics through the chemical composition and its potential application in hyperthermia treatment of cancer.

\section{Materials and Methods}

2.1. Preparation of $\mathrm{Fe}_{2} \mathrm{O}_{3}-\mathrm{CaO}-\mathrm{SiO}_{2}$ Glass Ceramics. Several different $\mathrm{Fe}_{2} \mathrm{O}_{3}-\mathrm{CaO}-\mathrm{SiO}_{2}$ glass ceramics samples were prepared by the sol-gel method and classified as groups $\mathrm{Al}$ and A2 (without phosphorous and with phosphorous, resp.).

The chemical compositions of the samples are shown in Table 1. The dosages of reagents calculated on the base of the chemical compositions were listed in Table 2. Briefly, the procedure involved preparing a solution of tetraethyl orthosilicate (TEOS) in ethanol. Distilled water was added to the solution such that the molar ratio of TEOS and water was $1: 15$. Then hydrochloric acid was added to the solution and stirred with a magnetic stirrer for $10 \mathrm{~min}$, and then calcium nitrate and iron nitrate were added to the solution. Triethyl phosphate was also added to the solution in group A2 at this time. The resulting solution was placed in a water bath at $45^{\circ} \mathrm{C}$ for $150 \mathrm{~min}$. Then the temperature was raised up to $65^{\circ} \mathrm{C}$ until the solution became semisolid. The samples were aged for 7 days at room temperature, and the gels obtained were baked in the drying oven at $120^{\circ} \mathrm{C}$ for $12 \mathrm{~h}$. Finally, the dried samples were heated to $650^{\circ} \mathrm{C}$ for an hour, followed by further heating at $950^{\circ} \mathrm{C}$ for 1 hour in a heat treatment furnace in a reducing atmosphere. The glass ceramic samples thus obtained were cooled to room temperature and characterized as described in the following sections.

2.2. Characterization. X-ray diffraction (XRD) analysis was performed with a XD-6 X-ray diffractometer at room temperature, with $\mathrm{CuK} \alpha$ radiation, $36 \mathrm{kV}$ voltage, and $20 \mathrm{~mA}$ current. X-ray data were collected in the $5<2 \theta<80$ range. Prior to the XRD test, the samples were ground into powder and sieved through a 300-mesh gauze.

Microarea elemental compositions of the samples were determined using a scanning electron microscopy (SEM) system (S-3400N) equipped with energy dispersive spectrometer (EDS). The samples were coated with a layer of gold approximately $10 \mathrm{~nm}$ thick, and the samples were analyzed for a live time of $30 \mathrm{~s}$. The total amounts of oxide in the samples were normalized to $100 \%$, and the $\mathrm{Fe}^{2+}$ and $\mathrm{Fe}^{3+}$ contents were converted to the equivalent $\mathrm{Fe}_{2} \mathrm{O}_{3}$ content.

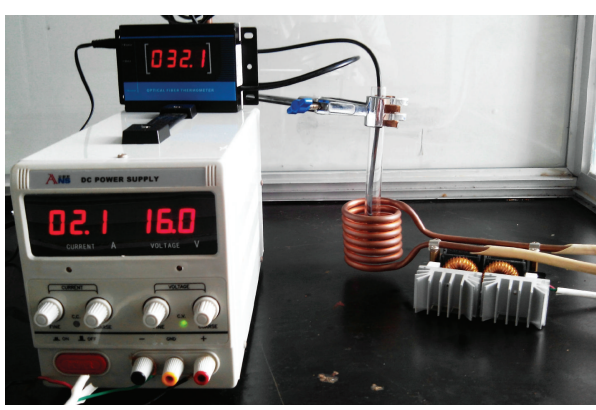

FIgURE 1: Homemade device for measuring induction heating ability.

Magnetization measurements were performed using a vibrating sample magnetometer (VSM, Lakeshore model 7407) at room temperature.

A homemade device was built for measuring the induction heating ability (Figure 1). The glass ceramics samples were introduced into a copper coil, which was part of a resonant RLC circuit producing an AC magnetic field in the frequency range $80 \mathrm{kHz}-100 \mathrm{kHz}$ and with amplitudes up to $0.15 \mathrm{kA} / \mathrm{m}$. The copper coil was cooled by circulating water, and the temperature was monitored using a fiber thermometer placed in the center of the sample. The induction heating ability was determined by plotting the initial linear rise in temperature versus time, normalized to the mass of the sample.

\section{Results and Discussion}

3.1. Crystal Phase Analysis. XRD patterns of the glass ceramic samples of group A1 are shown in Figure 2(a), demonstrating the presence of a mixture of crystalline phases for all the materials. Three major crystalline phases, wollastonite (JCPDS No. 84-0654), magnetite (JCPDS No. 85-1436), and hematite (JCPDS No. 85-0599) were observed in group A1 samples. The hematite level of sample A1S9 was much higher than those of other samples. XRD patterns of the glass ceramic samples of group A2 with phosphorus were characterized by the major hydroxyapatite phase (JCPDS No. 090432) in addition to the above three major crystalline phases (Figure 2(b)). Hydroxyapatite is the main constituent of bones, and the presence of this bone mineral phase along with the magnetic phase suggests both the biocompatible nature and the induction heating ability of the samples.

The relative mass of each phase, which was also calculated according to the XRD patterns, was listed in Table 3. The amounts of both magnetite and hematite phase of group A2 were more than that of group A1, and the increase of magnetite content indicates that the induction heating ability would get stronger.

3.2. Chemical Composition Analysis. The SEM-EDS spectra for the samples are shown in Figure 3. The results confirmed the presence of silicon, calcium, and iron in samples A1S5 and A1S7 while silicon, phosphorus, calcium, and iron were present in all the samples of group A2. Samples A1S5 and A1S7 
TABLE 2: The amount of the reagent.

\begin{tabular}{|c|c|c|c|c|c|}
\hline Sample & Iron nitrate $(\mathrm{g})$ & Calcium nitrate $(\mathrm{g})$ & TEOS (mL) & Triethyl phosphate $(\mathrm{mL})$ & Ethanol (mL) \\
\hline A1S1 & 3.62 & 8.43 & 7.60 & 0 & 22.80 \\
\hline A1S3 & 4.82 & 7.83 & 7.25 & 0 & 21.74 \\
\hline A1S5 & 6.03 & 7.22 & 6.89 & 0 & 20.68 \\
\hline A1S7 & 7.23 & 6.82 & 6.36 & 0 & 19.09 \\
\hline A1S9 & 8.44 & 6.42 & 5.83 & 0 & 17.50 \\
\hline $\mathrm{A} 2 \mathrm{P} 1$ & 7.23 & 8.03 & 5.30 & 0.12 & 15.91 \\
\hline A2P7 & 6.75 & 7.59 & 4.82 & 0.76 & 14.46 \\
\hline
\end{tabular}

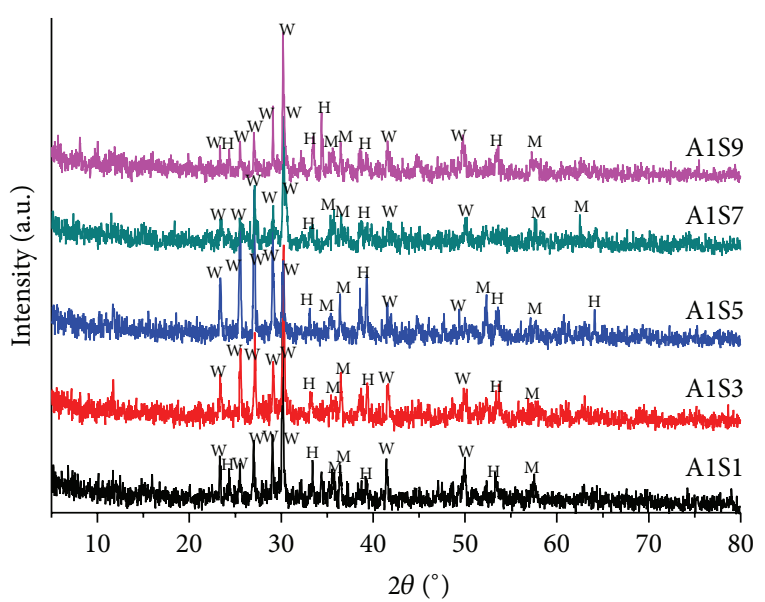

$\mathrm{H}$ : hematite M: magnetite

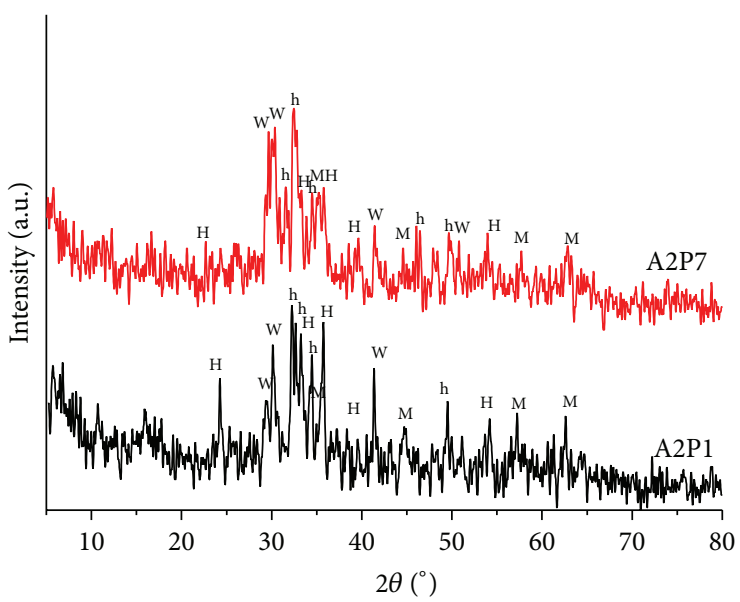

$\mathrm{H}$ : hematite M: magnetite
$\mathrm{W}$ : wollastonite h: hydroxyapatite

(a)

(b)

FIGURE 2: Room temperature XRD patterns of glass ceramic samples.

TABLE 3: The relative mass of the phases of the samples (wt\%).

\begin{tabular}{lcccc}
\hline Sample & Hematite & Magnetite & Wollastonite & Hydroxyapatite \\
\hline A1S1 & 4.7 & 2.8 & 92.5 & 0 \\
A1S3 & 2.5 & 2.6 & 94.8 & 0 \\
A1S5 & 2.4 & 1.6 & 96.1 & 0 \\
A1S7 & 3.8 & 4.8 & 91.4 & 0 \\
A1S9 & 5.9 & 4.2 & 89.9 & 0 \\
A2P1 & 15 & 6 & 45.1 & 33.9 \\
A2P7 & 7.5 & 4.5 & 50 & 38 \\
\hline
\end{tabular}

showed the presence of lathlike particles while the mineral particles in group A2 were granular. Moreover, the particle sizes of A2P1 were about $3 \mu \mathrm{m}$, which was much smaller than that of A1S7 which was about $16 \mu \mathrm{m}$. The chemical compositions of the samples calculated from EDS are given in Table 4. No other elements were identified, which ruled out the influence of impurities on the induction heating ability of the samples.

3.3. Magnetic Properties. Figure 4 shows the magnetization $(M-H)$ curves obtained for the samples as a function of applied magnetic field. The samples exhibit hysteresis with
TABLE 4: Chemical composition of the samples determined by SEMEDS (wt\%).

\begin{tabular}{lcccc}
\hline & $\mathrm{Fe}_{2} \mathrm{O}_{3}$ & $\mathrm{CaO}$ & $\mathrm{SiO}_{2}$ & $\mathrm{P}_{2} \mathrm{O}_{5}$ \\
\hline A1S5 & 28.71 & 37.75 & 33.54 & 0 \\
A1S7 & 22.73 & 32.79 & 45.01 & 0 \\
A2P1 & 32.57 & 34.26 & 30.40 & 2.76 \\
A2P7 & 32.05 & 30.95 & 25.31 & 11.70 \\
\hline
\end{tabular}

narrow hysteresis loop and low coercivity, suggesting the soft ferromagnetic nature of the samples. This is due to the formation of the magnetic phase upon heat treatment, as already confirmed by the XRD results.

The different magnetic parameters of the samples are listed in Table 5. Sample A1S7 shows higher saturation magnetization $M_{s}(19 \mathrm{emu} / \mathrm{g})$ and remanent magnetization $M_{r}$ $(2.3 \mathrm{emu} / \mathrm{g})$ than the other samples of group A1. This may be due to the enhancement in the magnetic phase in A1S7. However, $M_{s}$ and $M_{r}$ values began to decrease when the $\mathrm{Fe}_{2} \mathrm{O}_{3}$ content was over $30 \%$ (Figure 5), which can be attributed to the higher hematite content and the lower magnetite content. A2P1 has a lower saturation magnetization value but a larger coercive force compared to A1S7. The lower saturation magnetization may be attributed to some possible reactions 

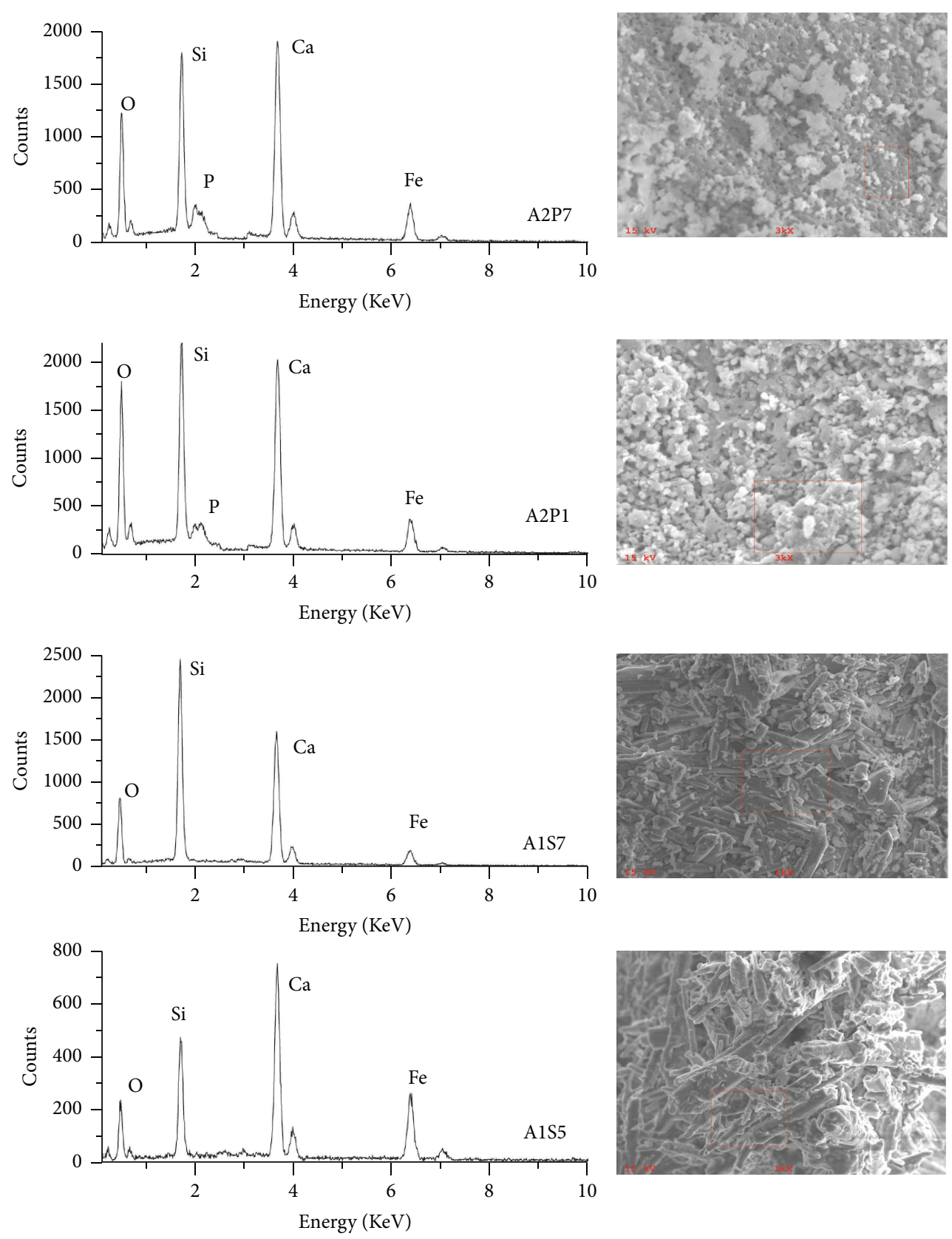

FIGURE 3: SEM-EDS spectra and images of the samples.

TABLE 5: Magnetic parameters of the samples.

\begin{tabular}{lccccccc}
\hline & A1S1 & A1S3 & A1S5 & A1S7 & A1S9 & A2P1 & A2P7 \\
\hline$H_{c}(\mathrm{G})$ & 147.76 & 124.82 & 206.83 & 106.24 & 82.45 & 113.85 & 87.87 \\
$M_{s}(\mathrm{emu} / \mathrm{g})$ & 1.99 & 2.06 & 3.32 & 19 & 17.09 & 10.99 & 10.65 \\
$M_{s}{ }^{*}(\mathrm{emu} / \mathrm{g})$ & 13.27 & 10.30 & 13.28 & 63.33 & 48.83 & 36.63 & 38.04 \\
$M_{r}(\mathrm{emu} / \mathrm{g})$ & 0.33 & 0.41 & 0.60 & 2.30 & 0.78 & 2.25 & 3.04 \\
Interpolated hysteresis area & 65649 & 176034 & 287151 & 1683193 & 525486 & 923229 & 980057 \\
\hline
\end{tabular}

Note: $M_{s}$ values were normalized to the total weight of the sample; $M_{s}{ }^{*}$ values were normalized to the weight of $\mathrm{Fe}_{2} \mathrm{O}_{3}$ component alone. 


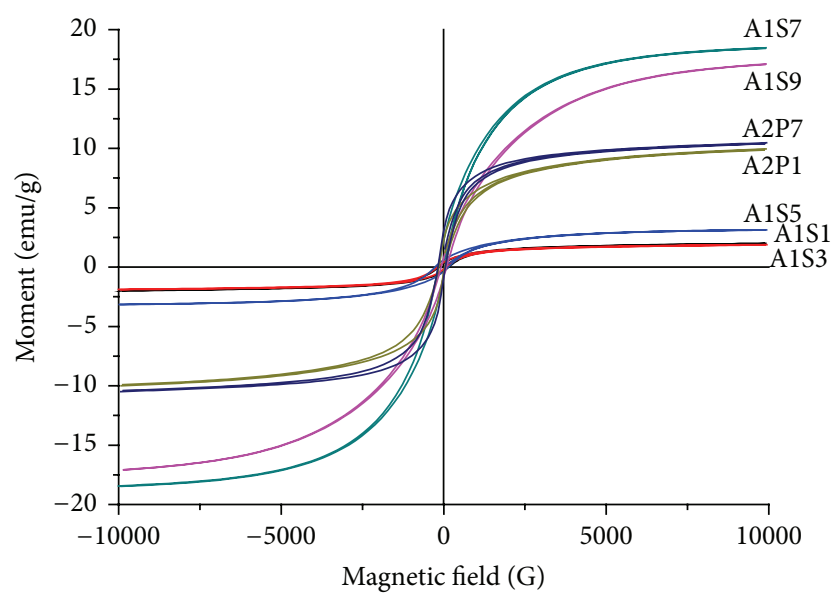

FIgURE 4: $M-H$ curves of the glass ceramic samples with different chemical composition.

during the heating process. It is a known fact that $\mathrm{P}_{2} \mathrm{O}_{5}$ and $\mathrm{SiO}_{2}$ can easily react with $\mathrm{Fe}_{2} \mathrm{O}_{3}$ forming nonmagnetic phases at high temperature [18]. Also, Fe could enter into the crystalline structure forming a solid solution [19]. The coercive field was also influenced in a significant way by the crystal dimensions [20]. The SEM results showed that the average crystallite size of $\mathrm{A} 2 \mathrm{P} 1$ was smaller than that of A1S7. The smaller crystallite size of the magnetic phase results in a larger coercive force. These observed phenomena were similar to previous reports [21].

Figure 5 shows the relationship between the different magnetic parameters and $\mathrm{Fe}_{2} \mathrm{O}_{3}$ content of the samples. The integrated hysteresis loop area was calculated for a maximum applied field of $10000 \mathrm{G}$. The relationship between integrated loop area and the $\mathrm{Fe}_{2} \mathrm{O}_{3}$ content was similar to that observed in the case of saturation magnetization. It can be seen from Figure 5 that the hysteresis loop area of AlS7 with $30 \% \mathrm{Fe}_{2} \mathrm{O}_{3}$ content is much larger than that of the other samples in group Al, which may be attributed to the higher remanence of A1S7. Theoretically, the energy generated by the glass ceramic samples under low magnetic field can be estimated from the hysteresis loop area [6]. Thus, the above results indicate that A1S7 should be capable of generating a larger amount of heat than the other samples, under a proper alternating magnetic field.

3.4. Induction Heating Ability. To test the heating ability of the samples, the induction heating experiments were performed with the different samples. Hyperthermia heating curves, measured at a fixed current of $2 \mathrm{~A}$ for $11 \mathrm{~min}$ with $1 \mathrm{~g}$ concentrations of the samples, are shown in Figure 6. The heating rates of the samples were basically the same, and the temperature increased rapidly until $10 \mathrm{~min}$. The temperature variation amplitudes of the samples were found to increase gradually with the increase of $\mathrm{Fe}_{2} \mathrm{O}_{3}$ content of the samples. However, the induction heating ability began to fall when the $\mathrm{Fe}_{2} \mathrm{O}_{3}$ content was over $30 \%$, which may be caused by the lower magnetite content. Sample A1S7 showed the largest temperature variation amplitudes of $2.7^{\circ} \mathrm{C}$ in group $\mathrm{A} 1$, which is consistent with the results in previous sections. More interestingly, the temperature variation amplitudes of all the
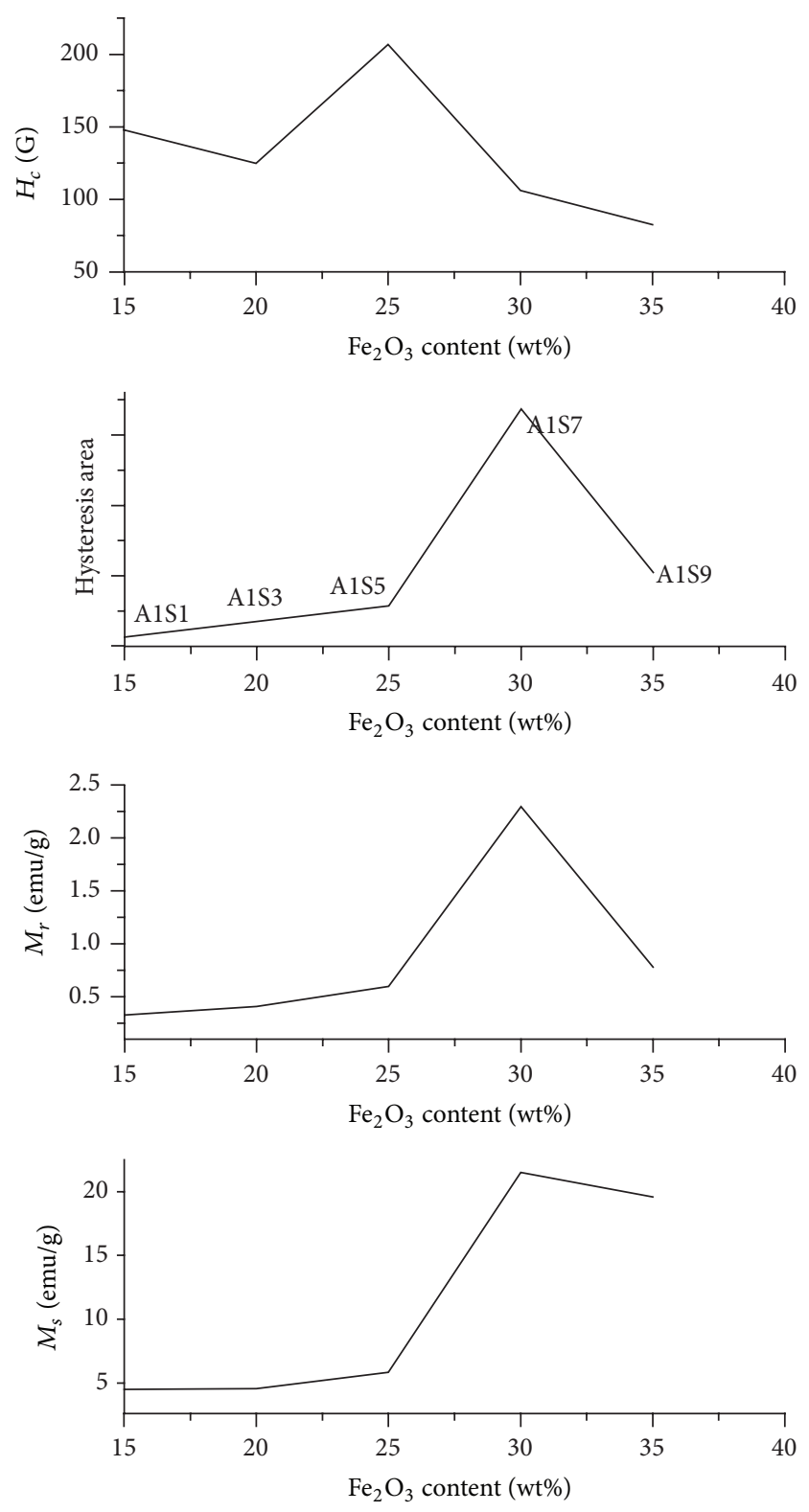

FIGURE 5: Relationship between magnetic properties and the $\mathrm{Fe}_{2} \mathrm{O}_{3}$ content.

samples in group $\mathrm{A} 1$ were about $2^{\circ} \mathrm{C}$, while the temperature variation amplitudes of the samples in group A2 with phosphorus were as high as $15^{\circ} \mathrm{C}$. The addition of phosphorus not only changed the crystalline phase of the samples but also significantly increased their induction heating ability. These results indicate that $\mathrm{P}_{2} \mathrm{O}_{5}-\mathrm{Fe}_{2} \mathrm{O}_{3}-\mathrm{CaO}-\mathrm{SiO}_{2}$ glass ceramics are more suitable for hyperthermia treatment than $\mathrm{Fe}_{2} \mathrm{O}_{3}$ $\mathrm{CaO}-\mathrm{SiO}_{2}$ glass ceramics.

In ferromagnetic materials, heat generation is mainly due to hysteresis loss. In addition, other physical parameters such as particle size and distribution of the components, as well as magnetic field intensity, also considerably influence the heating properties under AC magnetic field. The effect of these factors may be the reason for the ability of group A2 samples to generate more heat than group A1 samples. 

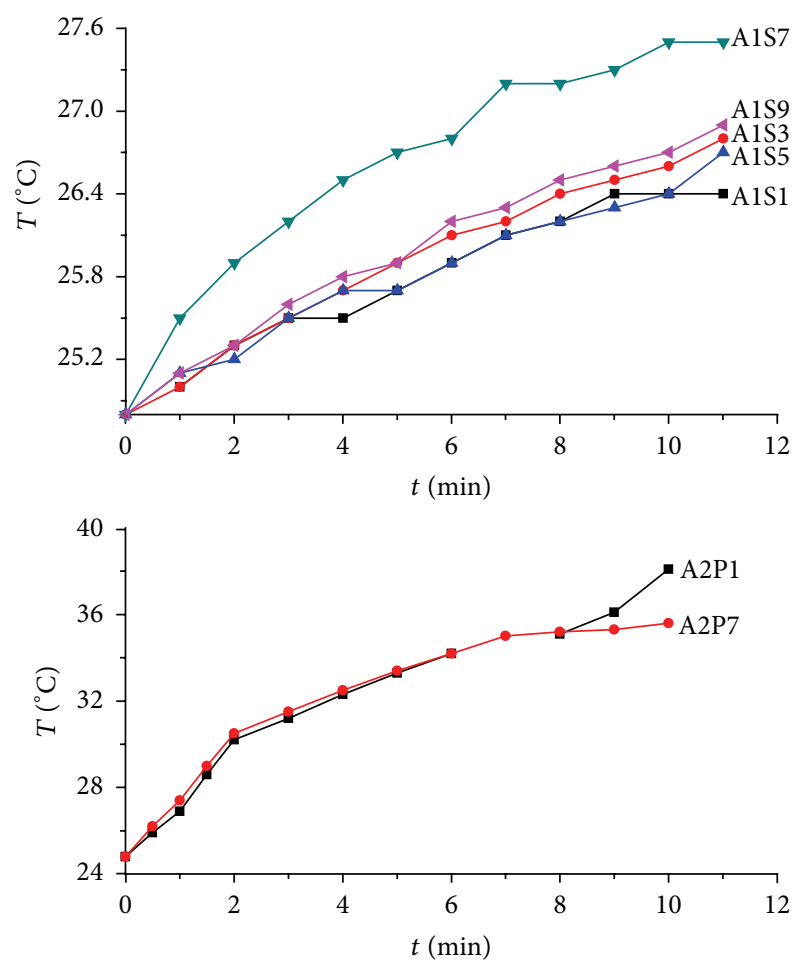

FIGURE 6: Temperature evolution as a function of time in the hyperthermia tests.

Further work is in progress in our laboratory to understand the heating properties of this class of glass ceramics and to optimize the composition for therapeutic application.

\section{Conclusions}

$\mathrm{Fe}_{2} \mathrm{O}_{3}-\mathrm{CaO}-\mathrm{SiO}_{2}$ glass ceramics of different compositions were prepared by the sol-gel method and tested for their induction heating ability. Magnetic properties of the glass ceramic samples were found to correlate with the $\mathrm{Fe}_{2} \mathrm{O}_{3}$ content. The saturation magnetization and the integrated loop area increased with the magnetite content in A1 group. Thus, the induction heating ability of A1S7 sample was the strongest among all the prepared $\mathrm{Fe}_{2} \mathrm{O}_{3}-\mathrm{CaO}-\mathrm{SiO}_{2}$ glass ceramics. Moreover, the induction heating ability was significantly improved when a small amount of phosphorus was introduced into the $\mathrm{Fe}_{2} \mathrm{O}_{3}-\mathrm{CaO}-\mathrm{SiO}_{2}$ glass ceramics. This reveals a promising methodology to control the magnetic properties of $\mathrm{Fe}_{2} \mathrm{O}_{3}-\mathrm{CaO}-\mathrm{SiO}_{2}$ glass ceramics through the chemical composition and its potential applications in hyperthermia treatment of cancer.

\section{Competing Interests}

The authors declare that they have no competing interests.

\section{Acknowledgments}

This research was financially supported by Natural Science Foundation for Youths of Zhejiang Province (LQ16E020001),
National Natural Science Foundation of China (no. 51372081), and Natural Science Foundation of Zhejiang Province (LY13E020006).

\section{References}

[1] P. Moroz, S. K. Jones, and B. N. Gray, "Magnetically mediated hyperthermia: current status and future directions," International Journal of Hyperthermia, vol. 18, no. 4, pp. 267-284, 2002.

[2] P. Wust, B. Hildebrandt, G. Sreenivasa et al., "Hyperthermia in combined treatment of cancer," The Lancet Oncology, vol. 3, no. 8, pp. 487-497, 2002.

[3] L. Treccani, T. Yvonne Klein, F. Meder, K. Pardun, and K. Rezwan, "Functionalized ceramics for biomedical, biotechnological and environmental applications," Acta Biomaterialia, vol. 9, no. 7, pp. 7115-7150, 2013.

[4] Y. Ebisawa, F. Miyaji, T. Kokubo, K. Ohura, and T. Nakamura, "Bioactivity of ferrimagnetic glass-ceramics in the system $\mathrm{FeO}$ $\mathrm{Fe}_{2} \mathrm{O}_{3}-\mathrm{CaO}-\mathrm{SiO}_{2}$," Biomaterials, vol. 18, no. 19, pp. 1277-1284, 1997.

[5] E. Ruiz-Hernández, M. C. Serrano, D. Arcos, and M. ValletRegí, "Glass-glass ceramic thermoseeds for hyperthermic treatment of bone tumors," Journal of Biomedical Materials Research A, vol. 79, no. 3, pp. 533-543, 2006.

[6] R. K. Singh, A. Srinivasan, and G. P. Kothiyal, "Evaluation of $\mathrm{CaO}-\mathrm{SiO}_{2}-\mathrm{P}_{2} \mathrm{O}_{5}-\mathrm{Na}_{2} \mathrm{O}-\mathrm{Fe}_{2} \mathrm{O}_{3}$ bioglass-ceramics for hyperthermia application," Journal of Materials Science: Materials in Medicine, vol. 20, no. 1, pp. S147-S151, 2009.

[7] Y. Y. Wang, B. Li, and Y. Y. Wang, "Characterization of $\mathrm{Fe}_{2} \mathrm{O}_{3}$ $\mathrm{CaO}-\mathrm{SiO}_{2}$ glass ceramics prepared by sol-gel," Applied Mechanics and Materials, vol. 624, pp. 114-118, 2014.

[8] Y.-K. Lee, S.-B. Lee, Y.-U. Kim et al., "Effect of ferrite thermoseeds on destruction of carcinoma cells under alternating magnetic field," Journal of Materials Science, vol. 38, no. 20, pp. 4221-4233, 2003.

[9] M. Matsumoto, N. Yoshimura, Y. Honda, M. Hiraoka, and K. Ohura, "Ferromagnetic hyperthermia in rabbit eyes using a new glass-ceramic thermoseed," Graefe's Archive for Clinical and Experimental Ophthalmology, vol. 232, no. 3, pp. 176-181, 1994.

[10] A. Matsumine, K. Kusuzaki, T. Matsubara et al., "Novel hyperthermia for metastatic bone tumors with magnetic materials by generating an alternating electromagnetic field," Clinical and Experimental Metastasis, vol. 24, no. 3, pp. 191-200, 2007.

[11] P. R. Stauffer, T. C. Cetas, A. M. Fletcher et al., "Observations on the use of ferromagnetic implants for inducing hyperthermia," IEEE Transactions on Biomedical Engineering, vol. 31, pp. 76-90, 1984.

[12] S. Mornet, S. Vasseur, F. Grasset, and E. Duguet, "Magnetic nanoparticle design for medical diagnosis and therapy," Journal of Materials Chemistry, vol. 14, no. 14, pp. 2161-2175, 2004.

[13] Y. Ebisawa, F. Mijaji, T. Kokubo et al., "Bioactivity of ferromagnetic glass-ceramics in the system $\mathrm{FeO}-\mathrm{Fe}_{2} \mathrm{O}_{3}-\mathrm{CaO}-\mathrm{SiO}_{2}$," Biomaterials, vol. 18, no. 19, pp. 1277-1284, 1997.

[14] O. Bretcanu, E. Verné, M. Cöisson, P. Tiberto, and P. Allia, "Magnetic properties of the ferrimagnetic glass-ceramics for hyperthermia," Journal of Magnetism and Magnetic Materials, vol. 305, no. 2, pp. 529-533, 2006.

[15] Y.-K. Lee, K.-N. Kim, S.-Y. Choi, and C.-S. Kim, "Effect of iron state on crystallization and dissolution in $\mathrm{Fe}_{2} \mathrm{O}_{3}-\mathrm{CaO}-\mathrm{SiO}_{2}$ glasses," Journal of Materials Science: Materials in Medicine, vol. 11 , no. 8, pp. 511-515, 2000. 
[16] O. Bretcanu, S. Spriano, E. Verné, M. Cöisson, P. Tiberto, and P. Allia, "The influence of crystallised $\mathrm{Fe}_{3} \mathrm{O}_{4}$ on the magnetic properties of coprecipitation-derived ferrimagnetic glassceramics," Acta Biomaterialia, vol. 1, no. 4, pp. 421-429, 2005.

[17] N. Shankhwar, G. P. Kothiyal, and A. Srinivasan, "Understanding the magnetic behavior of heat treated $\mathrm{CaO}-\mathrm{P}_{2} \mathrm{O}_{5}-\mathrm{Na}_{2} \mathrm{O}-$ $\mathrm{Fe}_{2} \mathrm{O}_{3}-\mathrm{SiO}_{2}$ bioactive glass using electron paramagnetic resonance studies," Physica B, vol. 448, pp. 132-135, 2014.

[18] Z. Zhigang, Ferrite Magnetic Material, Science Press, Beijing, China, 1981.

[19] Y. Ohashi and L. W. Finger, "The role of octahedral cations in pyroxenoid crystal chemistry. I. Bustamite, wollastonite, and the pectolite-schizolite-serandite series," American Mineralogist, vol. 63, pp. 274-288, 1978.

[20] S. Chikazumi, S. Taketomi, M. Ukita et al., "Physics of magnetic fluids," Journal of Magnetism and Magnetic Materials, vol. 65, no. 2-3, pp. 245-251, 1987.

[21] R. K. Singh and A. Srinivasan, "Bioactivity of ferrimagnetic $\mathrm{MgO}-\mathrm{CaO}-\mathrm{SiO}_{2}-\mathrm{P}_{2} \mathrm{O}_{5}-\mathrm{Fe}_{2} \mathrm{O}_{3}$ glass-ceramics," Ceramics International, vol. 36, no. 1, pp. 283-290, 2010. 

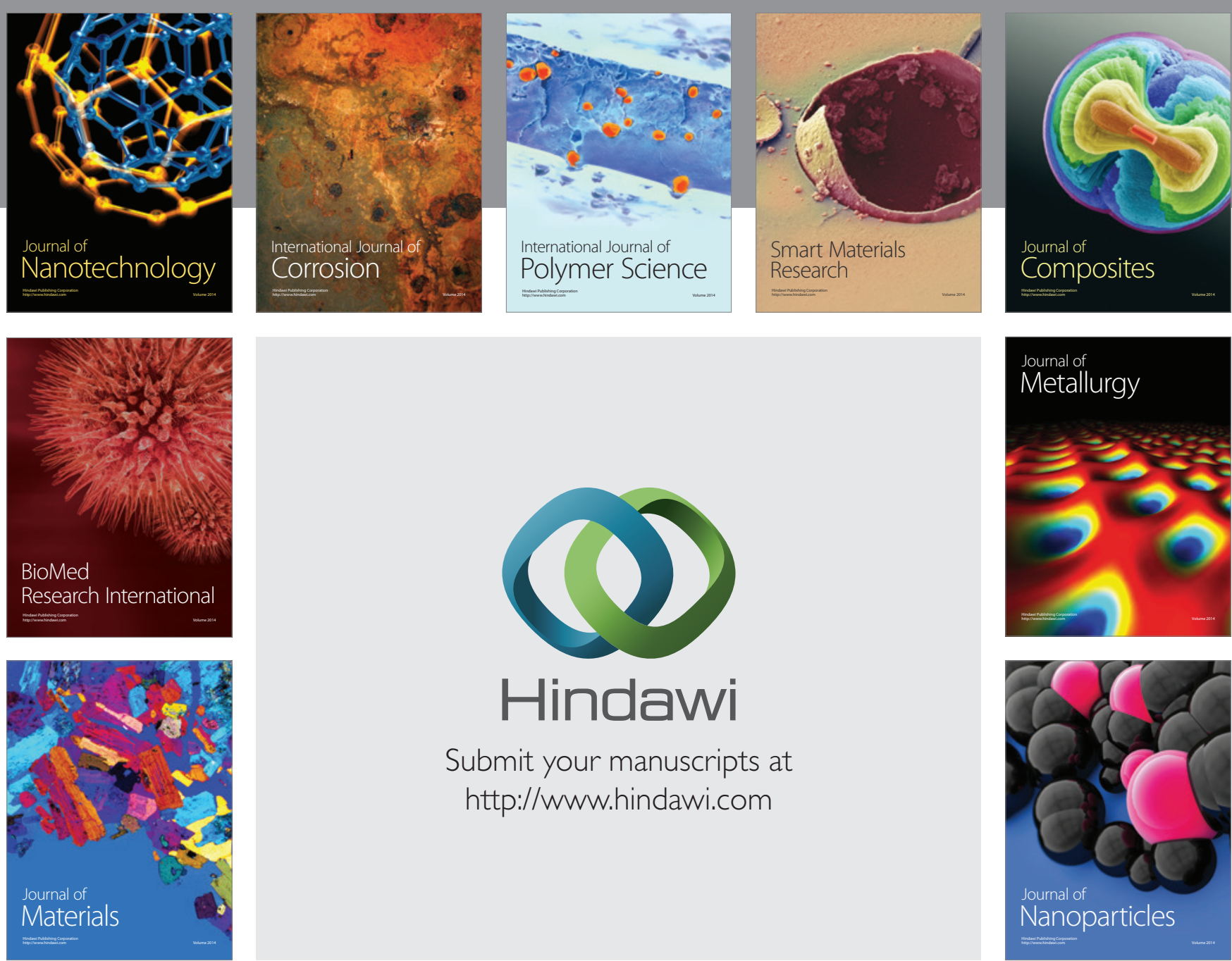

\section{Hindawi}

Submit your manuscripts at

http://www.hindawi.com

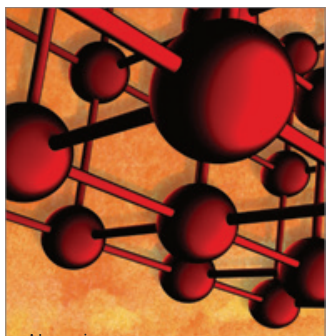

Materials Science and Engineering
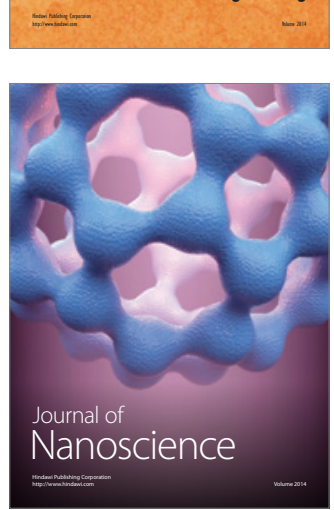
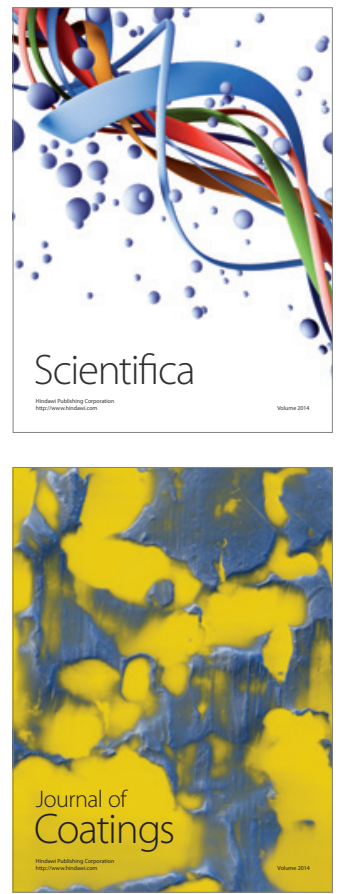
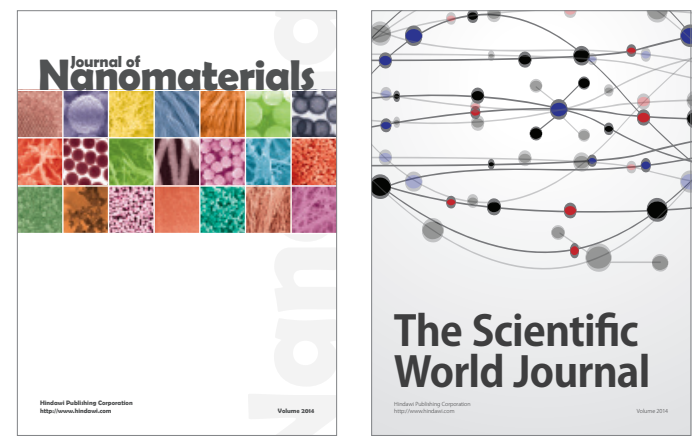

The Scientific World Journal
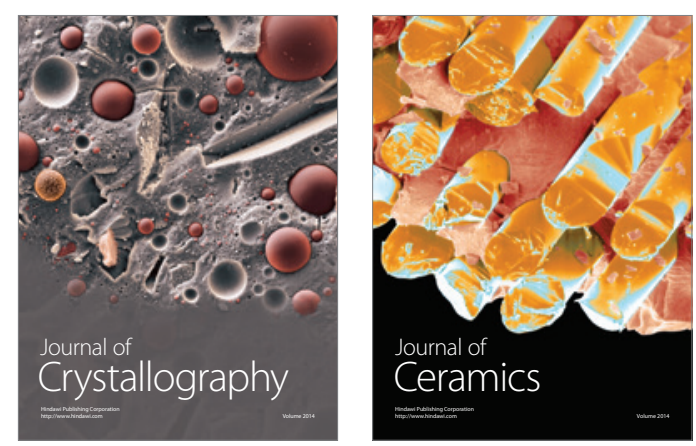
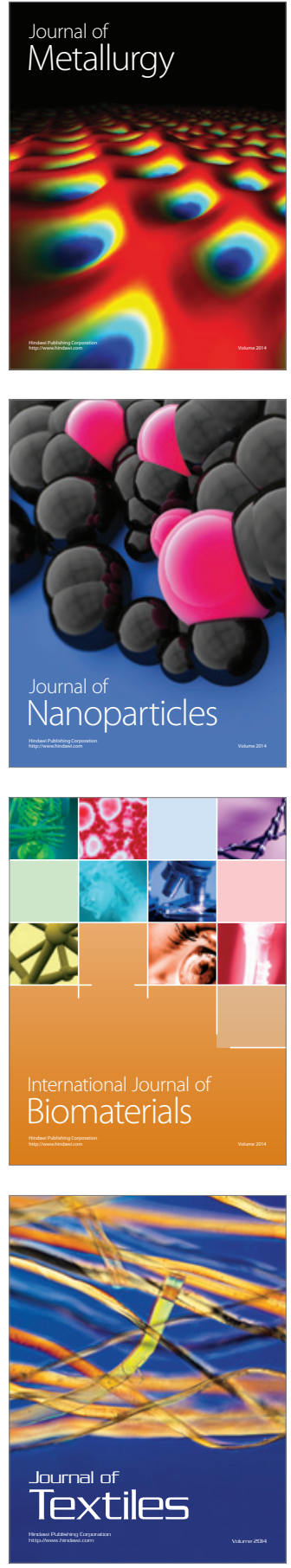